\title{
Docking Evaluation of Catechin and its Derivatives on Fat Mass and Obesity-Associated (FTO) Protein For Anti-Obesity Agent
}

\author{
Tony Sumaryada ${ }^{1,2, *}$, Renti Efraim Marimpola Simamora ${ }^{3}$, Laksmi Ambarsari ${ }^{2,3}$ \\ ${ }^{1}$ Computational Biophysics and Molecular Modeling Research Group (CBMoRG), Department of Physics, Bogor Agricultural University, Jalan Meranti \\ Kampus IPB Dramaga Bogor 16680, Indonesia. \\ ${ }^{2}$ Tropical Biopharmaca Research Center, Bogor Agricultural University, Jalan Taman Kencana No. 3, Bogor 16128, Indonesia. \\ ${ }^{3}$ Department of Biochemistry, Bogor Agricultural University, Jalan Agatis Kampus Dramaga IPB, 16880, Indonesia.
}

\section{ARTICLE INFO \\ Article history: \\ Received on: $10 / 12 / 2017$ \\ Accepted on: 28/03/2018 \\ Available online: 31/08/2018}

\section{Key words:}

catechin derivatives, green

tea, FTO protein, obesity,

molecular docking.

\begin{abstract}
In this paper, we report the docking analysis and performance of catechin and its derivatives in inhibiting the FTO (Fat mass and obesity-associated) protein for controlling the obesity problem. The results show that Arg-52 and Tyr-39 residues play role in hydrogen binding, while Trp-42, Pro-47, and Ile-50 play role in hydrophobic interactions between ligands and the FTO enzyme. All catechin and its derivatives, except epicatechin, show a promising potential as FTO inhibitor as shown by their binding affinity $(\Delta G)$ values which are lower than the binding affinity of the patented drug, orlistat $(-6.2 \mathrm{kCal} / \mathrm{mol})$. The gallocatechin compound was found to be the best FTO inhibitor with the binding affinity of $\Delta \mathrm{G}=-7.70 \mathrm{kCal} / \mathrm{mol}$ and the binding site similarity to orlistat of $63.6 \%$.
\end{abstract}

\section{INTRODUCTION}

Green tea has been known for many centuries to have numerous benefits to human's health due to its high level of flavonoid compounds. Those compounds, catechin and its derivatives (epicatechin, gallocatechin, and epigallocatechin) have been proven to have anti-diabetic, antioxidant, anti-obesity, antibacterial, anti-inflammation, anti-viral, and anti-cancer potential (Cabrera et al., 2006; Lee et al., 2014; Reygaert et al., 2014; Kumar et al., 2015; Balachandran et al., 2015; Cui et al., 2015; Mohammed et al., 2015). The healing mechanism of catechin and its derivatives on various health's problems has become one of the most active research nowadays, including the molecular interaction standpoint.

Obesity recently becomes a global health problem with the alarming number of prevalences. The obesity itself is not

\footnotetext{
*Corresponding Author

Tony Sumaryada, Computational Biophysics and Molecular Modeling Research Group (CBMoRG), Department of Physics, Bogor Agricultural University, Jalan Meranti Kampus IPB Dramaga Bogor 16680,

Indonesia.E-mail: tsumaryada@ipb.ac.id
}

defined as a disease but rather as a disease process which can end up in various health problems (Lobstein et al., 2017). The obesity is indicated at people with the body mass index bigger then 30 (Whitlock et al., 2009). There are many biochemistry pathways and mechanisms which could lead to a metabolic syndrome problem such as obesity, one of them is through the inhibition of the FTO (Fat mass and Obesity-Associated) protein (Gerken et al., 2007). The FTO protein plays an important role in regulating the fat accumulation in the body, so the excessive expression of this protein might lead to the increase of the metabolism for fat and obesity (Sudeep and Shyam, 2014). Another mechanism to decelerate the progression of obesity including the stimulation of hepatic lipid metabolism by long-term consumption of catechin compounds from the green tea's extract (Murase et al., 2002).

There have been numerous molecular docking studies between FTO protein with flavonoids such as quercetin, apigenin, naringenin (Zhang et al., 2017), taiwaniaquinoids (Ren et al., 2016), and flavonols (Wang et al., 2017). All those ligands are about the same size of catechins (quercetin of $302.238 \mathrm{~g} / \mathrm{mol}$, letrozole of $285.31 \mathrm{~g} / \mathrm{mol}$, apigenin of $270.24 \mathrm{~g} / \mathrm{mol}$, naringenin of $272.256 \mathrm{~g} / \mathrm{mol}$, and taiwaniaquinoids of $302.414 \mathrm{~g} / \mathrm{mol}$ ), but to 
the best of authors' knowledge there is no specific docking study of catechins on FTO target to treat the obesity problem. This paper is aimed to explore the potential of catechin and its derivatives as FTO inhibitor to treat the obesity problem via a docking method. The docking simulations were performed between catechin (and its derivatives) ligands and FTO protein as the target. The patented obesity drugs, orlistat (Drew et al., 2007), were used as a control ligand. By comparing the inhibition profiles of catechin and its derivatives with the control ligand, we will investigate the molecular mechanism of catechins binding with FTO protein and determine whether catechins have a potential to replace orlistat in inhibiting FTO as an anti-obesity agent.
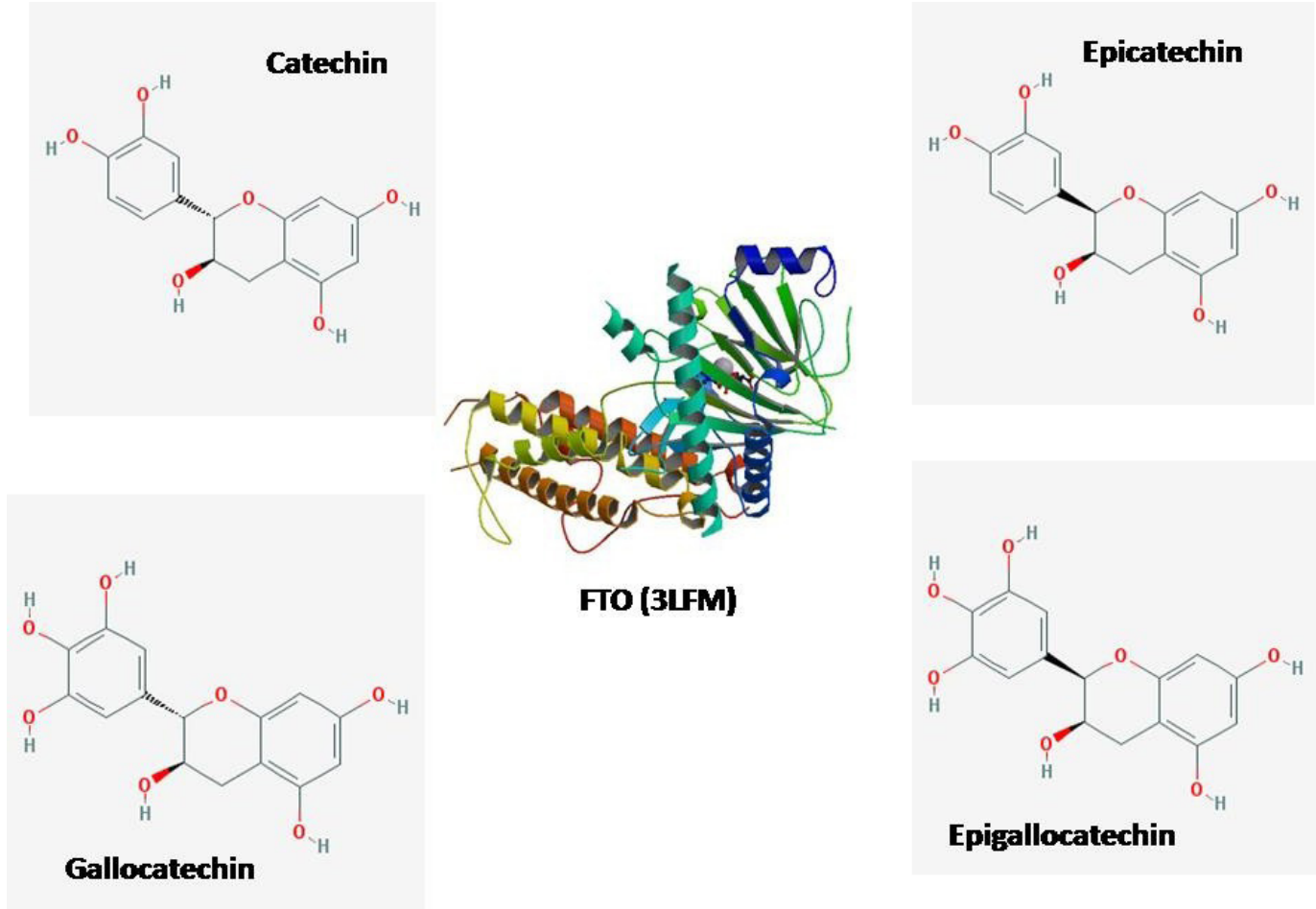

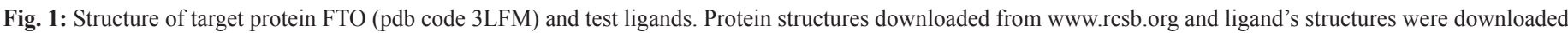
from http://pubchem.ncbi.nlm.nih.gov.

\section{MATERIAL AND METHODS}

The three-dimensional structure of FTO protein (PDB code 3LFM) was downloaded from www.rcsb.org (Han et al., 2010). The receptor's structure data were downloaded and opened using Discovery studio 3.5 Client program to remove the natural ligand that still attached to it. Before the docking process, the nonpolar hydrogen atoms were added, followed by Gasteiger charges calculation using Autodock tools (ADT) 1.5.6. (Morris et al., 2009). The protein file then saved in PDBQT format and ready to be used for docking.

There are five ligands prepared for docking simulation, four catechin and its derivatives (as test ligands) and one patented drugs, orlistat, as a control ligand. The three-dimensional structure of ligands was downloaded from PubChem database (Figure 1), opened and saved in PDB format using Marvin View 6.0 software. The polar hydrogen atoms were added and Gasteiger charges were assigned using Discovery Studio 3.5 Client program. All ligands have to be saved in PDBQT format.

The docking simulations of ligands and target protein were performed using AutoDockVina (Trott and Olson, 2010) program. Targeted docking method was used in this research with the coordinate of origin was set at $\mathrm{x}=20.062, \mathrm{y}=-8.993$ and $\mathrm{z}=$ -28.47 . This set of numbers was based on the location of orlistat binding with FTO. The box size was set at $\mathrm{x}=40, \mathrm{y}=40$ and $\mathrm{z}=$ 40. The number of modes in the docking simulations was set to 20 to get accurate results.

The docking analysis was conducted based on the value of binding affinities and the binding site similarity (BSS) between ligands and control ligand. Two types of interaction that analyzed in this research are, hydrogen bond and hydrophobic interaction. Interaction occurred between amino acids of the target and functional groups of the ligand. The binding site similarity analysis between test ligands and the standard ligand, orlistat were performed using LigPlot 1.4.5 program (Laskowski and Swindells, 2011).

\section{RESULT AND DISCUSSION}

Before conducting the docking simulation, it is important to check the likeliness of the compounds as a drug by using the Lipinski's criteria (Lipinski et al., 2000). Based on the Lipinski rules, the molecular weight of the promising drug compounds must less than $500 \mathrm{~g} / \mathrm{mol}$, the maximum number of donor atom is 5 , and the maximum number of acceptor atom is 10 , the value of $\log \mathrm{P}$ must be below 5 . It was found that catechin and its derivatives mostly fulfilled those requirements and can be further evaluated using docking method (Table 1). 
The docking simulation results are shown in Table 2 . Orlistat as the standard ligand has been successfully docked on FTO protein with the binding affinity score of $\Delta \mathrm{G}=-6.20 \mathrm{kCal} /$ mol as seen in Figure 2. The binding sites of orlistat on FTO target includes two residues involved in the hydrogen bond and nine residues involved in the hydrophobic interactions. The strongest binding occurred between the $\mathrm{COO}^{-}$functional group of Glu-156 in the FTO target and the OH5 functional group of orlistat with the bond length of $2.84 \AA$. Another hydrogen bond, but not as strong as the previous one was formed between the $\mathrm{NH} 2$ functional group of Arg-52 and the CO4 functional group of orlistat.

Table 1: Lipinski's evaluation of the ligands.

\begin{tabular}{|c|c|c|c|c|c|}
\hline Structure & Formula & Molecular weight (g/mol) & $\log P$ & $\begin{array}{l}\text { The number of atomic donor involved in } \\
\text { H-bond }\end{array}$ & $\begin{array}{c}\text { The number of atomic acceptor involved } \\
\text { in H-bond }\end{array}$ \\
\hline Catechin & $\mathrm{C}_{15} \mathrm{H}_{14} \mathrm{O}_{6}$ & 290.26806 & 1.80 & 5 & 6 \\
\hline Epicatechin & $\mathrm{C}_{15} \mathrm{H}_{14} \mathrm{O}_{6}$ & 290.26806 & 1.80 & 5 & 6 \\
\hline Gallocathecin & $\mathrm{C}_{15} \mathrm{H}_{14} \mathrm{O}_{7}$ & 306.26746 & 1.49 & 6 & 7 \\
\hline Epigallocatechin & $\mathrm{C}_{15} \mathrm{H}_{14} \mathrm{O}_{7}$ & 306.26746 & 1.49 & 6 & 7 \\
\hline Orlistat & $\mathrm{C}_{29} \mathrm{H}_{53} \mathrm{NO}_{5}$ & 495.73480 & 8.11 & 1 & 3 \\
\hline
\end{tabular}

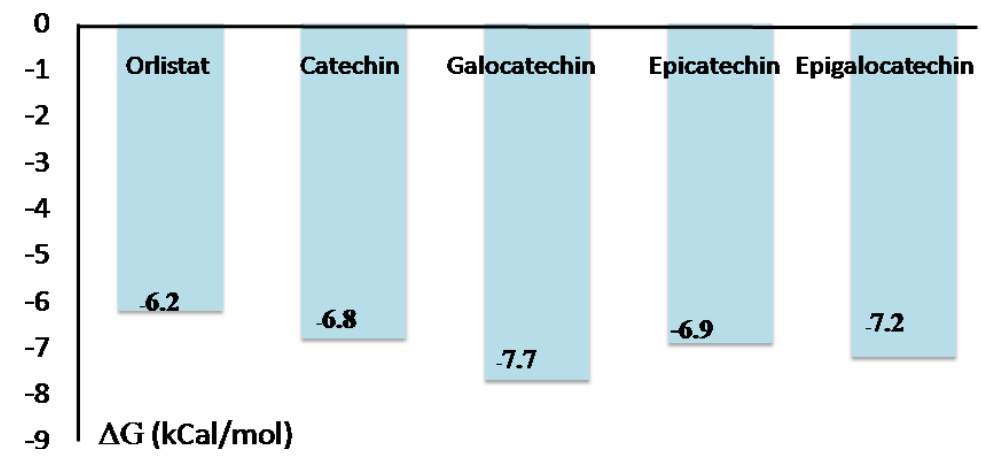

Fig. 2: The binding affinity of catechin and its derivatives on FTO protein as compared to the patented drug for obesity, orlistat.

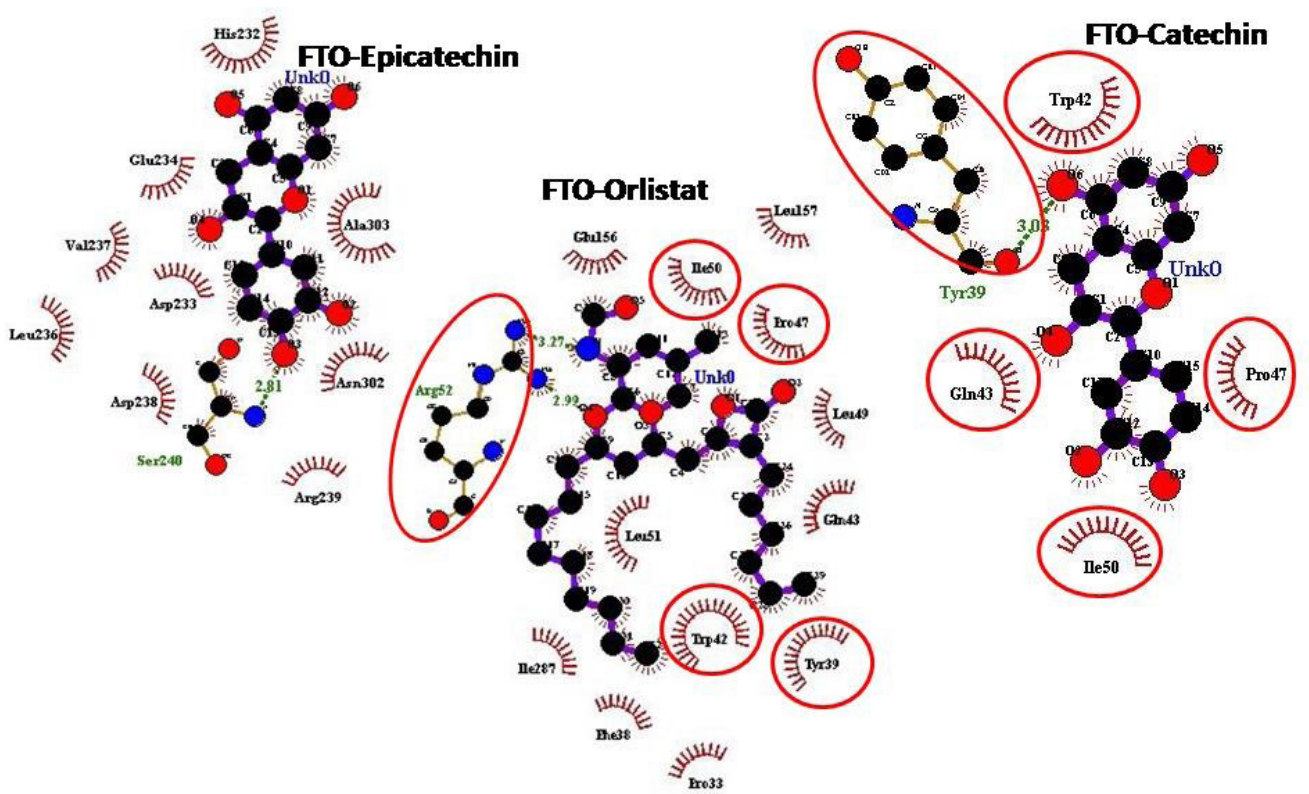

Fig. 3: The binding sites similarity of catechin and epicatechin on FTO protein target as compared to orlistat's, the patented drug. The detailed name of amino acids involved in the interactions is given in Table 2.

The binding of Catechin to FTO consist of one hydrogen bond between the $\mathrm{COO}^{-}$functional group of Tyr-39 with the OH6 functional group of catechin with the bond length of $3.00 \AA$ (Figure 3). The binding affinity score of catechin to FTO protein is $\Delta \mathrm{G}=-6.80 \mathrm{kCal} / \mathrm{mol}$.
There are four out of nine hydrophobic interactions of orlistat, which are identical to catechin's and assure that some parts of catechin reside in the same pocket as orlistat's as shown by the binding site similarity scores of $45.4 \%$ (Table 2 ).

Different results of binding were found in the binding of 
epicatechin which resides in the different pocket as orlistat (Figure $3)$, even though it has better binding affinity than orlistat $(\Delta \mathrm{G}=$ $-6.90 \mathrm{kCal} / \mathrm{mol}$ ). This stronger binding of epicatechin as compared to orlistat came from the strong hydrogen bond (bond length of $2.82 \AA$ ) between functional group $\mathrm{OH} 3$ with $\mathrm{NH} 2$ functional group of Ser-240 residue. Although, epicatechin in this simulation has no binding site similarity with orlistat and other catechin derivatives, three residues which involved in hydrophobic interactions (His232, Asp-233, Gln-234) were found in two hydrogen bonds (Asp233, Gln-234) and one hydrophobic interaction (His-232) between letrozole drug (PubChem CID 3902) and FTO (Mohammed et al., 2015). This indicates that epicatechin might act as an aromatase inhibitor as letrozole does in FTO.

Table 2: Docking simulation results.

\begin{tabular}{|c|c|c|c|c|c|c|}
\hline Test ligand & $\begin{array}{l}\text { Hydrogen bond } \\
\text { length }(\AA)\end{array}$ & $\begin{array}{l}\text { Residue involved } \\
\text { in } \mathrm{H} \text { - bonding }\end{array}$ & $\begin{array}{l}\text { Functional } \\
\text { group of ligand }\end{array}$ & $\begin{array}{c}\text { Residue involved in Hydrophobic } \\
\text { interaction }\end{array}$ & $\begin{array}{l}\text { Binding site similarity } \\
\text { to standard ligand (\%) }\end{array}$ & $\begin{array}{l}\text { Binding Affinity } \\
\Delta G(\mathrm{kCal} / \mathrm{mol})\end{array}$ \\
\hline \multirow{2}{*}{ Orlistat (standard ligand) } & 2.84 & Glu-156 & OH5 & \multirow{2}{*}{$\begin{array}{c}\text { Phe-38, Tyr-39, Trp-42, Gln-43, } \\
\text { Pro-47, Leu-49 Ile-50. Leu-51, } \\
\text { Leu-157 }\end{array}$} & \multirow{2}{*}{100} & \multirow{2}{*}{-6.20} \\
\hline & 2.95 & Arg-52 & $\mathrm{CO} 4$ & & & \\
\hline Catechin & 3.00 & Tyr-39 & OH6 & $\begin{array}{l}\text { Trp-42, Gln-43, } \\
\text { Pro-47, Ile-50 }\end{array}$ & 45.4 & -6.80 \\
\hline Epicatechin & 2.82 & Ser-240 & $\mathrm{OH} 3$ & $\begin{array}{c}\text { His-232, Asp-233, } \\
\text { Glu-234, Leu-236, Val-237, Asp-238, } \\
\text { Arg-239, Asn-302, Ala-303 }\end{array}$ & 0 & -6.90 \\
\hline \multirow{4}{*}{ Gallocatechin } & 2.09 & Tyr-39 & $\mathrm{OH} 7$ & \multirow{4}{*}{$\begin{array}{c}\text { Trp-42, Gln-43, } \\
\text { Pro-47, Ile-50 }\end{array}$} & \multirow{4}{*}{63.6} & \multirow{4}{*}{-7.70} \\
\hline & 3.04 & $\operatorname{Arg} 52$ & $\mathrm{OH} 2$ & & & \\
\hline & 3.20 & $\operatorname{Arg} 52$ & $\mathrm{OH} 2$ & & & \\
\hline & 3.21 & Leu-51 & OH5 & & & \\
\hline \multirow{3}{*}{ Epigallocatechin } & 2.95 & Tyr-39 & $\mathrm{OH} 7$ & \multirow{3}{*}{ Trp-42, Pro-47, Ile-50 } & \multirow{3}{*}{45.4} & \multirow{3}{*}{-7.20} \\
\hline & 3.07 & Arg-52 & $\mathrm{OH} 4$ & & & \\
\hline & 3.07 & Arg-52 & $\mathrm{OH} 4$ & & & \\
\hline
\end{tabular}

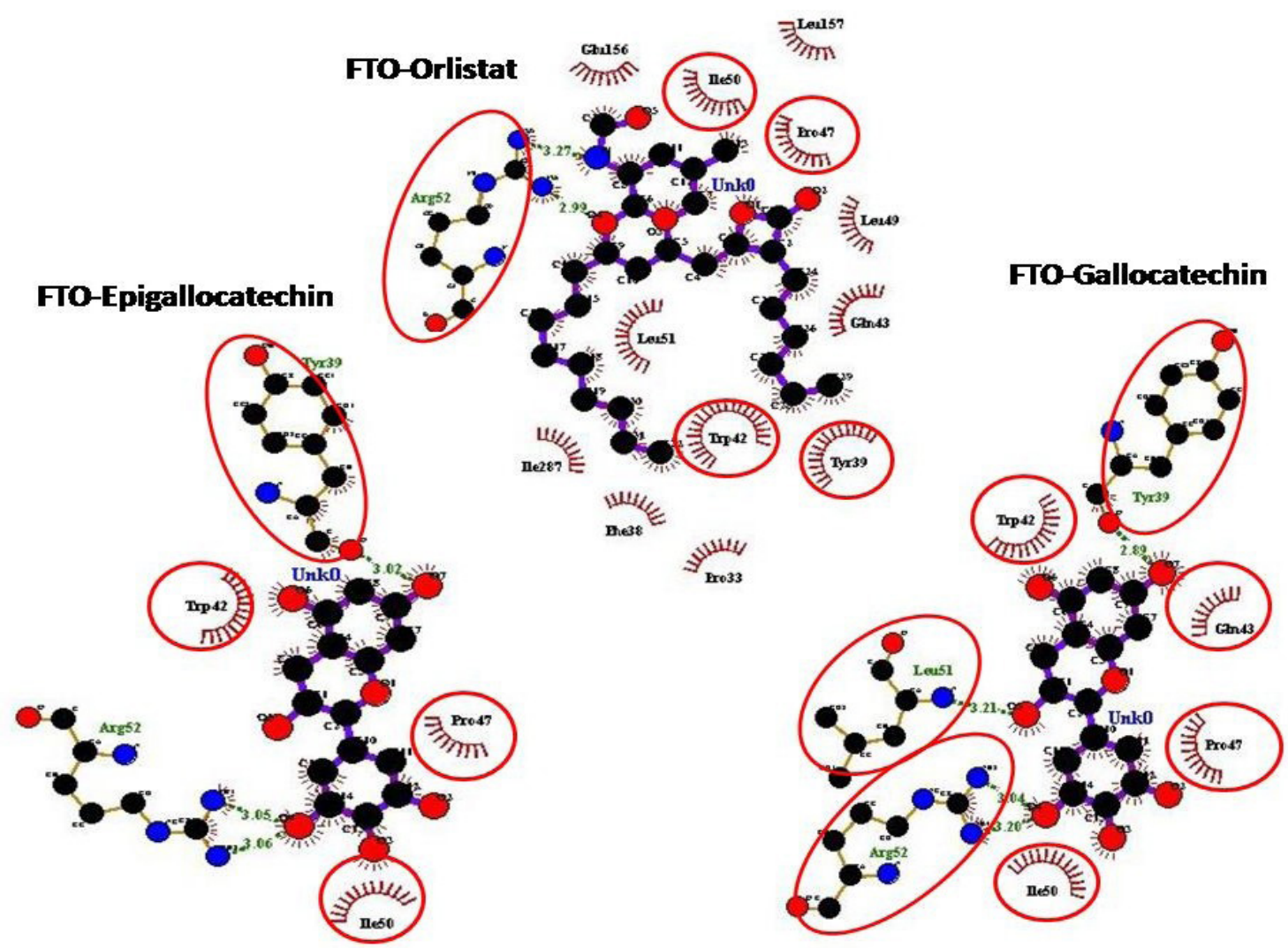

Fig. 4: The binding sites similarity of gallocatechin and epigallocatechin on FTO protein target as compared to orlistat's, the patented drug. The detailed name of amino acids involved in the interactions is given in Table 2. 
The binding of gallocatechin to FTO target was characterized by the occurrence of four hydrogen bonds which make a stronger binding affinity $(\Delta \mathrm{G}=-7.70 \mathrm{kCal} / \mathrm{mol})$ than orlistat (Figure 4). Three out of four hydrogen bonds involves Arg-52 and Tyr-39, which also present in orlistat's binding site. Four hydrophobic interactions of gallocatechin also occurred within the same pocket as orlistat and catechin (Trp-42, Gln-43, Pro-47, Ile-50). The binding site similarity score of gallocatechin is $63.6 \%$ (Table 2). Other research on catechin binding (Cui et al., 2015) has also signified the role of Trp and Gln amino acids in forming the hydrophobic interaction with catechin's functional groups.

The last compound evaluated is epigallocatechin, where three hydrogen bonds formed consist of interaction between functional group $\mathrm{OH} 4$ of epigallocatechin and a $\mathrm{COO}^{-}$group from Tyr-39, and functional group $\mathrm{OH} 7$ and $\mathrm{NH} 2$ group of Arg-52 (Figure 4). The binding affinity of this compound to FTO protein was $\Delta \mathrm{G}=-7.20 \mathrm{kCal} / \mathrm{mol}$, which mostly came from three hydrogen bonds as explained above. The absence of hydrophobic interaction with Gln-43 and hydrogen bond of the hydroxyl group with Leu-51 weaken the epigallocatechin's binding to FTO protein as compared to gallocatechin's. The binding site similarity score of epigallocatechin as compared to orlistat's is $45.4 \%$ (Table 2) and mostly came from the hydrophobic sites.

From the analysis above, the hydrophobic interactions of Trp-42, Pro-47, Ile-50 is found to be continuously present in the orlistat, catechin, gallocatechin, and epigallocatechin binding mode. This found indicates that those three amino acids in FTO protein provide a stable pocket for the compounds to reside and inhibit the FTO protein. Two residues in FTO protein, Tyr-39, and Arg-52 also play role in locking the functional groups of the compounds (orlistat, catechin, gallocatechin, and epigallocatechin) to be in the vicinity of the targeting pocket via hydrogen bonding. This finding is in accord with the docking study of three flavonoids (quercetin, apigenin, and naringenin) with FTO protein (Zhang et al., 2017) which revealed the importance of not just hydrophobic interaction but also hydrogen bonding of some ionic and polar residues of FTO. We have also found that epicatechin in our simulation was docked in the completely different pocket as compared to other compounds. The nine hydrophobic interactions of epicatechin indicate that this compound might deeply-trapped in the different pocket as compared to other catechins due to the interaction of its $\mathrm{OH} 3$ functional group.

\section{CONCLUSION}

Molecular docking simulation of catechin and its derivatives on FTO protein has been performed to explore the potential of those compounds in inhibiting the target. Catechin and its derivatives, except epicatechin, have exhibited a stronger binding with FTO protein as compared to the patented drug, orlistat. Gallocatechin has shown the best potential to be developed into anti-obesity drugs followed by epigallocatechin and catechin. Except for epicatechin, all ligands, in general, docked on the same pocket as orlistat's which indicates that catechin and its derivatives followed the same biochemistry pathway in inhibiting the FTO protein. This study has also revealed that two residues of FTO involved in hydrogen bond (Tyr-39 and Arg-52), and three residues involved in the hydrophobic interaction (Trp-42, Pro-47,
Ile-50) were crucial in the molecular interaction between catechins and FTO protein.

\section{ACKNOWLEDGMENT}

The authors express their gratitude for the funding from the Directorate of Higher Education, Ministry of Education and Culture Republic of Indonesia through BOPTN research grant contract number 237/IT3.41.2/L2/SPK/2013 code 2013.089.521219. The authors also express their gratitude to the anonymous reviewers for their valuable critics and suggestions.

\section{REFERENCES}

Balachandran C, Kumar PS, Arun Y, Duraipandiyan V, Sundaram RL, Vijayakumar A, Balakrishna K, Ignacimuthu S, Al-Dhabi NA, Perumal PT. Antimicrobial, antioxidant, cytotoxic and molecular docking properties of N-benzyl-2, 2, 2-trifluoroacetamide. Applied Nanoscience. 2015; 5(2):207-216

Cabrera C, Artacho R, Giménez R. Beneficial effects of green tea-a review. Journal of American College Nutrition. 2006; 25:79-99.

Cui F, Yang K, Li Y. Investigate the Binding of Catechins to Trypsin Using Docking and Molecular Dynamics Simulation. PLoS ONE. 2015; 10(5):e0125848

Drew BS, Dixon AF, Dixon JB. Obesity management: update on orlistat. Vasc Health Risk Manag. 2007; 3(6):817-21.

Gerken T. The obesity-associated FTO gene encodes a 2-oxoglutarate-dependent nucleic acid demethylase. Science. 2007; 318:1469-1472.

Han Z, Niu T, Chang J, Lei X, Zhao M, Wang Q, Cheng W, Wang J, Feng Y, Chai J. Crystal structure of the FTO protein reveals basis for its substrate specifity. Nature. 2010; 464:1205-1208.

Kumar D, Poornima M, Kushwaha RN, Won TJ, Ahn C, Kumar CG, Jang K, Shin DS. Antimicrobial and docking studies of (-)-catechin derivatives. Journal of the Korean Society for Applied Biological Chemistry. 2015; 58(4):581-585

Laskowski RA, Swindells MB. LigPlot+: Multiple LigandProtein Interaction Diagrams For Drug Discovery. Journal of Chemical Information and Modeling. 2011; 51(10): 2778-2786.

Lee LS, Kim SH, Kim YB, Kim YC. Quantitative analysis of major constituents in green tea with different plucking periods and their antioxidant activity. Molecules. 2014; 19(7):9173-9186.

Lipinski CA. Drug-like properties and the causes of poor solubility and poor permeability. Journal of Pharmacological and Toxicological Methods. 2000; 44:235-249.

Lobstein T, Brinsden H, Gill T, Kumanyika S, Swinburn B. Comment: obesity as a disease - some implications for the World Obesity Federation's advocacy and public health activities. Obesity Reviews. 2017; 18:724-726.

Mohammed A, Al-Numair KS, Balakrishnan A. Docking studies on the interaction of flavonoids with fat mass and obesity associated protein. Pakistan Journal of Pharmaceutical Sciences. 2015; 28(5):1647-1653.

Morris GM, Huey R, Lindstrom W, Sanner MF, Belew RK, Goodsell DS, Olson AJ. AutoDock4 and AutoDockTools4: Automated docking with selective receptor flexibility. Journal of Computational Chemistry. 2009; 30(16):2785-2791.

Murase T, Nagasawa A, Suzuki J, Hase T, Tokimitsu I. Beneficial effects of tea catechins on diet-induced obesity: stimulation of lipid catabolism in the liver. International Journal of Obesity. 2002; 26(11):1459.

Ren T, Zhang L, Wang J, Song C, Wang R, Chang J. Study on the interaction of taiwaniaquinoids with FTO by spectroscopy and molecular modeling. Journal of Biomolecular Structure and Dynamics. 2016; 35(14):3182-3193.

Reygaert WC. The antimicrobial possibilities of green tea. Frontiers in microbiology. 2014; 5(434):1-8.

Sudeep HV, Shyam PK. Computational studies on the antiobesity 
effect of polyphenols from pomegranate leaf. Journal of Chemical and Pharmaceutical Research. 2014; 6(9):278-281.

Trott O, Olson AJ. AutoDock Vina: Improving the speed and accuracy of docking with a new scoring function, efficient optimization, and multithreading. Journal of Computational Chemistry. 2010; 31(2):455461.

Wang Z, Wang N, Han X, Wang R, Chang J. Interaction of two flavonols with fat mass and obesity-associated protein investigated by fluorescence quenching and molecular docking. Journal of Biomolecular Structure and Dynamics. 2017; DOI: 10.1080/07391102.2017.1388287.

Whitlock G, Lwington S, Sherliker P, Clarke R, Emberson J, Halsey J, Qizilbash N, Collins R, Peto R. Body-mass index and cause-specific mortality in 900000 adults: collaborative analyses of 57 prospective. The Lancet. 2009; 373(9669):1083-1096.
Zhang L, Re T, Wang Z, Wang R, Chang J. Lambert JD, Ju J, Lu G, Sang S. Comparative study of the binding of 3 flavonoids to the fat mass and obesity-associated protein by spectroscopy and molecular modeling. Journal of Molecular Recognition. 2017; 30:e2606.

How to cite this article:

Sumaryada T, Simamora REM, Ambarsari L. Docking Evaluation of Catechin and its Derivatives on Fat Mass and Obesity-Associated (FTO) Protein For Anti-Obesity Agent. J App Pharm Sci, 2018; 8(08): 063-068. 